University of Nebraska - Lincoln

DigitalCommons@University of Nebraska - Lincoln

Papers in Biotechnology

Chemical and Biomolecular Engineering

Research and Publications

March 2006

\title{
A Comparative Study of Monoclonal Antibodies (Mabs) Purified from Cell Culture Supernatant on EDTPA-Modified Zirconia Beads and Protein A-Hyper D Support
}

\author{
Anuradha Subramanian \\ Department of chemical Engineering,University of Nebraska Lincoln., asubramanian2@unl.edu \\ Blanca Martinez \\ Biosystems and Agricultural Engineering, University of Minnesota, St. Paul, Minnesota \\ Jill Holm \\ Biosystems and Agricultural Engineering, University of Minnesota, St. Paul, Minnesota \\ Peter W. Carr \\ Department of Chemistry, University of Minnesota, Minneapolis, Minnesota. \\ Clayton V. McNeff \\ Zirchrom, Anoka, Minnesota
}

Follow this and additional works at: https://digitalcommons.unl.edu/chemeng_biotechnology

Part of the Biochemical and Biomolecular Engineering Commons

Subramanian, Anuradha; Martinez, Blanca; Holm, Jill ; Carr, Peter W. ; and McNeff, Clayton V. , "A Comparative Study of Monoclonal Antibodies (Mabs) Purified from Cell Culture Supernatant on EDTPAModified Zirconia Beads and Protein A-Hyper D Support" (2006). Papers in Biotechnology. 25.

https://digitalcommons.unl.edu/chemeng_biotechnology/25

This Article is brought to you for free and open access by the Chemical and Biomolecular Engineering Research and Publications at DigitalCommons@University of Nebraska - Lincoln. It has been accepted for inclusion in Papers in Biotechnology by an authorized administrator of DigitalCommons@University of Nebraska - Lincoln. 


\section{A Comparative Study of Monoclonal Antibodies (Mabs) Purified from Cell Culture Supernatant on EDTPA-Modified Zirconia Beads and Protein A-Hyper D Support}

Abstract:

Colloidal zirconia was spray dried to yield zirconia particles, which were further modified with $\mathrm{N}, \mathrm{N}, \mathrm{N} 0, \mathrm{~N} 0$ - Ethylenediamine tetra methylenephosphonic acid (EDTPA) to yield a support for use in bioseparations. EDTPA modified zirconia particles will be further referred to as, r_PEZ. Cell culture supernatants rich in monoclonal antibody (Mab) subtypes IgG1, IgG2a, IgG2b, and IgG3 were chromatographed on a r_PEZ column, and on a protein A-hyper D column that was purchased commercially. All Mab subtypes bound to r_PEZ and process yields in the range of 88 to $99 \%$ were obtained. The purity of the Mab products were ascertained by gel lectrophoretic analysis and were estimated to be greater than $95 \%$. The purified Mab products obtained from r_PEZ and protein A columns were compared to the reference Mab standard in biological and enzymatic assays. The value of the dissociation constant (Kd) was found to be comparable and was in the range to that obtained with reference Mab standard $(0.231+0.03 \mathrm{M})$. In addition, Mabs purified with r_PEZ had the same deglycosylation profile as the reference Mab standard. Thus, it appears that the r_PEZ purified Mab is similar in activity to Mab purified with a protein A support and in addition, the zirconia surface does not adversely impact the activity of the purified Mab.

\section{INTRODUCTION}

The importance of immunoglobulins (Ig's) has been well researched and documented.[1] The unique specificity that an antibody displays for an antigen makes it an invaluable tool in diagnostics[2,3] as probes for fine structural analysis, [4,5] in histological examination,[6] and in immunotherapy.[7] Purified immunoglobulin products have been used for medi- 
cal treatment in patients with inadequate Ig levels.[8] As the discovery of new medical and diagnostic uses for immunoglobulins arise, an increased need for medicalgrade Ig's will continue to fuel advances in the area of Ig separation. There is a demand in the current market to design and develop methodologies for the purification of human globulin from plasma or from genetically engineered sources. Purification schemes for Ig's include precipitation with ammonium sulfate, gel filtration chromatography, ion-exchange chromatography,[ 9] thiophilic chromatography,[10] and affinity separations using immobilized protein-A.[4,11,12] Protein A affinity chromatography is a technique that has long been used for IgG isolation[13] and recently, protein $\mathrm{G}$ with a broader range of specificity has also been used in IgG isolation. The usage of both protein $A$ and protein $G$ in affinity chromatography is negatively impacted by the harsh elution conditions necessary for the reverse binding reaction to take place. In addition, the use of both protein $A$ and protein $G$ as affinity supports in chromatographic columns poses special challenges regarding regeneration and sanitation.[14] Also, a negative consequence of using this method is the leakage of immobilized protein A and protein $G$ (whole protein and fragments) that results in the contamination of the eluted immunoglobulins.[15] This is detrimental because protein $A$ has been linked with toxicity in both animals and humans.[16] Although protein A mimetic ligands have shown promise, ligand leakage and column regeneration are still sources of potential shortcomings. Although protein A affinity chromatography is a popular step in protein purifications, the need for less expensive, more stable alternatives to this technique has prompted many researchers to turn their attentions to the development of synthetic ligands. The techniques developed using pseudo- A. bioaffinity ligands have proven to avoid the risks associated with toxicities in elution fractions due to ligand leakage. Additionally, these ligands typically provide for a mild elution environment, thereby retaining immunological properties of the protein, have broader immunoglobulin specificity, and are more stable in chromatographic systems in comparison to ligands such as protein A and G.[17] The use of histidyl 
and thiophilic ligands are limited due to their lack of specificity and selectivity. Metal chelate interaction chromatography using Cupp-chelate gel has been studied for the separation of Ig from blood serum and plasma.[18,19] However, concern of metal ligand leakage in the eluant presents a drawback. Additionally, the strength of bonding of the metal ion to the support, so that residual affinity for proteins remains, is often difficult to achieve.[20] The preparation of alternative stationary phase supports is an important area that aims to develop new support materials that offer novel selectivities or overcome the shortcomings of existing supports. Hence, there was an interest to develop adsorbents that operated based on physiochemical affinities or on mixed mode synthetic chemistries coupled with engineered matrices.[28] The development of EDTPA modified zirconia as a stationary phase material is an example where both aspects may be achieved. Studies have established the usefulness of $r_{-} P E Z$ as a chromatographic stationary phase[21 - 27] in HPLC applications and in the efficient purification of antibodies.[29] The aim of this study is to compare the activities of antibody products purified on r_PEZ and protein A_hyper D support. The impact, if any, of the zirconiabased stationary phase on the activities of antibodies will be evaluated.

\section{EXPERIMENTAL}

\section{Reagents}

All chemicals were of analytical grade or better. Sodium chloride was purchased from Fischer Scientific (Hanover Park, IL, USA). N, N, N0, NO- Ethylenediamine tetra methylenephosphonic acid (EDTPA) was purchased from TCI America (Portland, OR, USA). Bovine serum albumin (BSA), pure human immunoglobulin $G(H \lg G)$, all horseradish peroxidase conjugated antiimmunoglobulins used for ELISA, and human serum albumin (HSA) were obtained from Sigma 
Chemical Company (St. Louis, MO, USA). All proteins were used without further purification. Cell culture supernatant rich in Mab subclasses $\lg G 1$, IgG2a, IgG2b, and IgG3 was purchased from SOBIO (Southern Biotechnology Institute, Birmingham, AL). Pure Mab standards (subclasses) were also purchased from SOBIO. Rabbit anti-human Protein C (P-4680), goat antimouse IgG (A-4416), and calcium chloride $(\mathrm{CaCl} 2)$ were purchased from Sigma (St. Louis, MO). Purified human protein C (hPC-239F) was purchased from American A Comparative Study of Monoclonal Antibodies 473 Diagnostica Inc. (Greenwich, CT). O-Phenylenediamine$2 \mathrm{HCl}(\mathrm{OPD})$ tablets were purchased from Abbot Laboratories (Chicago, IL). Reference Mab was provided as a generous gift by Dr. William Velander (Virginia Tech, Blacksburg, VA). PNGase F Kit was obtained from New England BioLab Inc. (Beverly, MA). NuPage 4-12\% BisTris gels were purchased from Invitrogen (Carlsbad, CA). Gelcode for staining was obtained from Pierce (Rockford, IL). Immulon II microtiter plates were purchased from Fisher Scientific (Hanover Park, IL, USA). Affinity purified goat anti-mouse (whole molecule) immunoglobulins and goat anti-mouse immunoglobulins conjugated to horseradish peroxidase (HRP) were purchased from Sigma Chemical Company (St. Louis, MO, USA). A GenesysTM 5 model from Spectronic Instruments UV-visible spectrophotometer (Rochester, NY, USA) was used to record the adsorption measurements. A bench top microcentrifuge (Eppendorf Centrifuge 5415C) was used to sediment the r_PEZ particles for batch experiments. Chromatography. EDTPA modified particles were packed in $20 \mathrm{~cm} \_1.0 \mathrm{~cm}$ (i.d.) $\mathrm{cm}$ and provided by Zirchrom, Inc. The chromatographic system used was a HPLC system using a Spectroflow 783 detector at $280 \mathrm{~nm}$ and an isocratic pump from Chromtech (Apple Valley, MN). For separation and isolation of $\lg \mathrm{G} 1,2 \mathrm{a}, 2 \mathrm{~b}, 3$ from the cell culture supernatant, a protocol similar to that described elsewhere was adopted.[27] In a separate experiment, $2.0 \mathrm{~mL}$ protein A immobilized on hyper D support was packed into a Pharmacia column $\left(1.0 \mathrm{~cm} \_10.0 \mathrm{~cm}\right)$ and cell culture supernatants were chromatographed according to the manufacturer's instructions. In a typical appli- 
cation, $1 \mathrm{~mL}$ of supernatant was diluted with $1.0 \mathrm{~mL}$ of $0.5 \mathrm{M}$ sodium citrate buffer at $\mathrm{pH} 8.4$ (LB1). Feed was filtered using a Millipore 0.45 microns membrane filter and loaded on to the column at a linear velocity of $1.25 \mathrm{~cm} / \mathrm{min}$. Loosely bound proteins were washed with LB1. The elution of the bound Mab was effected with $0.5 \%$ acetic acid. The $\mathrm{pH}$ of the elution fraction was immediately raised to 7.0 with $1 \mathrm{M}$ Tris-base. All chromatographic fractions were saved and analyzed for total protein content at OD $280 \mathrm{~nm}$, Mab content by specific ELISA assays and electrophoretic analysis. SDS-PAGE Analysis and Western Blot SDS-PAGE analysis under non-reducing and reducing conditions were performed using Novex electrophoresis system. Gels were stained with Gelcode to visualize the protein bands.[30] Western blots were performed with nitrocellulose membranes using standard procedures and DAB substrate was used to visualize the bands. Enzymatic Deglycosyation of Mab Standard and purified Mab of $100 \mathrm{~mL}$ from r_PEZ column and protein A-hyper $\mathrm{D}$ at $50 \mathrm{mg} / \mathrm{mL}$ were denatured with $5 \mathrm{~mL}$ of 10X denaturing buffer for $5 \mathrm{~min}$ at 958C. Upon cooling to room temperature, $6 \mathrm{~mL}$ of $10 \mathrm{X} \mathrm{G7}$ buffer and $6 \mathrm{~mL}$ of $10 \% \mathrm{NP}-40$ was added. Of the enzyme, $3 \mathrm{~mL}$ were added to each reaction tube and incubated for $1 \mathrm{hr}$ at $378 \mathrm{C}$. The deglycosylated proteins were analyzed by western blotting. Estimation of Kd Costar microtiter plates were coated with $100 \mathrm{~mL}$ per well of 0.5 $\mathrm{mg} / \mathrm{mL}$ of pure $\mathrm{hPC}$ for $24 \mathrm{hr}$ at $48 \mathrm{C}$. Plates were washed three to four times with $\mathrm{TBS} / 0.2 \%$ Tween-20 buffer and blocked with $200 \mathrm{uL}$ of TBS/0.1\% BSA buffer for $60 \mathrm{~min}$ at room temperature. Mabs (Mab purified with r-PEZ, Mab purified with protein A, Mab provided by Dr. Subramanian) at 40 and $20 \mathrm{ng} / \mathrm{mL}$ were incubated with pure $\mathrm{hPC}$ at various $\mathrm{Ag} / \mathrm{Ab}$ ratios (40 to $0.078 \mathrm{~mol} / \mathrm{mol}$ ) in TBS $/ 0.1 \%$ BSA-25mM EDTA buffer for $24 \mathrm{hr}$ at $48 \mathrm{C}$. Triplicate application of $100 \mathrm{~mL}$ of Mab:hPC dilutions were pipetted into the coated plates. The plates were incubated for 8 minutes at RT. After washing the plates three times with TBS/Tween buffer, the complex was detected by addition of 1:1000th diluted goat anti-mouse HRP conjugate (A-4416) and in- 
cubated for $1 \mathrm{hr}$ at $378 \mathrm{C}$. The bound chromophorei was detected with OPD, and the reaction was stopped with $3 \mathrm{~N} \mathrm{H} 2 \mathrm{SO} 4$. Absorbance was measured at $490 \mathrm{~nm}$.

\section{RESULTS}

Expression Level and Purification Yields Experiments to characterize the performance of $r \_P E Z$ were performed with commercially available, pure, Mab subclasses. In order to identify the elution and retention profiles pure Mab were chromatographed on the EDTPA modified zirconia column. As judged by the chromatographic trace at $280 \mathrm{~nm}$, most of the Mab was retained on the matrix and was eluted at five column volumes. A model solution, which mimics the target stream from which Mabs would be isolated (i.e., a cell culture supernatant), was produced by mixing BSA and Mab to gauge the ability of the modified zirconia phase to efficiently separate the Mab from other contaminating proteins present in the cell culture supernatant. No retention of either BSA on the matrix was observed, as judged by a large peak eluting at the dead volume of the column (data not shown). The Mab was well retained on the EDTPA modified zirconia column and eluted at 5 column volumes. A Comparative Study of Monoclonal Antibodies. Chromatographic profiles with similar characteristics to one described elsewhere[27] were obtained for the isolation of Mab from the cell culture supernatant and a representative profile is shown in Figure 1, panel B. A representative chromatographic profile for the isolation of Mab from cell culture supernatant on commercially purchased protein-A column is shown in Figure 1, panel A. The profile of the elution peak on a r_PEZ column was sharp and was approximately between 4 to 6 column volumes. In our experience, the elution peak on an immobilized protein-A column was asymmetric with shoulders and tailing. No visible peaks were observed in the regeneration step in either of the columns tested. Table 1 summarizes the total protein recovery and Mab yield in the eluate fractions for both $r_{-} P E Z$ and 
protein-hyper D columns. The Mab concentration in different chromatographic fractions in each individual run was estimated by the ELISA assays. The percent yield of Mab in the eluate fraction was determined as a ratio of the total Mab in the eluate fraction to the total Mab challenge. In most cases, total Mab recoveries of $80-99 \%$ were obtained. The r_PEZ column runs shown in Table 1 had Mab yields (based on ELISA) of in the range of $60 \%$ to $93 \%$, while the protein A-hyper D column runs had Mab yields of in the range of $73 \%$ to $100 \%$, respectively, with little or no detectable Mab in column fall through and wash fractions.
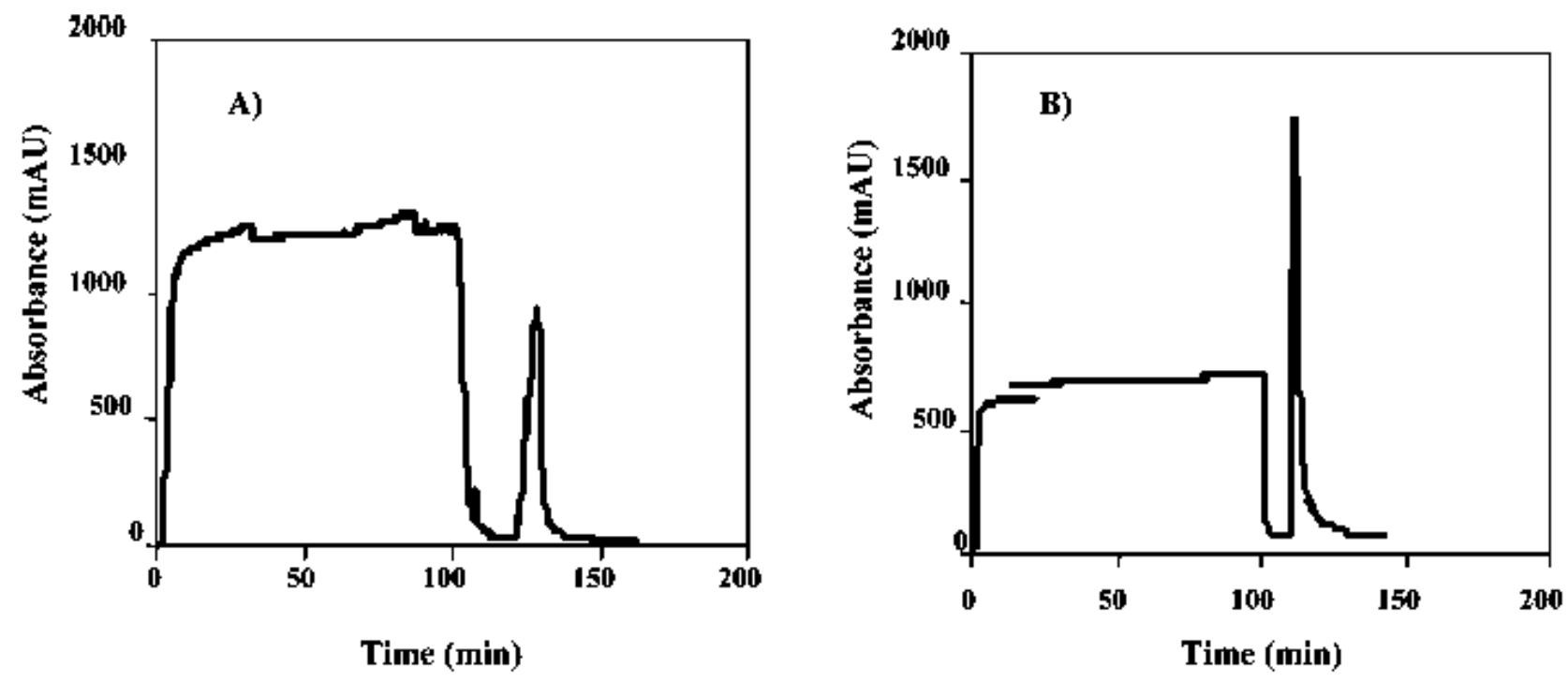

Figure 1. Separation of Mab on various chromatography columns. (A) Protein A on hyper-D and (B) EDTPA modified zirconia. EDTPA modified particles were packed in $15 \mathrm{~cm} \_1.0 \mathrm{~cm}$ (i.d.) $\mathrm{cm}$ and provided by Zirchrom, Inc. The chromatographic system used was a HPLC system using a spectroflow 783 detector at $280 \mathrm{~nm}$ and an isocratic pump from Chromtech (Apple Valley, MN). Diluted Mab-rich supernatant was loaded dynamically, loosely bound proteins were washed, and bound Mab was eluted with $1 \mathrm{M} \mathrm{NaCl}$. All chromatographic operations were preformed at a linear flow rate of $6.37 \mathrm{~mL} / \mathrm{min}$. Protein A immobilized on hyper D support was packed into a Pharmacia according to the manufacturer's instructions. Loosely bound proteins were washed with loading buffer and the bound Mab was eluted with $0.5 \%$ acetic acid. All chromatographic fractions were saved and analyzed for total protein content at OD $280 \mathrm{~nm}$, Mab content by specific ELISA assays and electrophoretic analysis. 
Table 1. Summary of chromatographic runs

\begin{tabular}{|c|c|c|c|c|c|}
\hline \multicolumn{2}{|c|}{ r_PEZ column } & \multicolumn{2}{|c|}{ Based on OD $280 \mathrm{~nm}$} & \multicolumn{2}{|c|}{ Based on ELISA } \\
\hline Sample & & $\% \mathrm{TR}$ & $\%$ yield & $\% \mathrm{TR}$ & $\%$ yield \\
\hline Sup'nt-IgG1 & $\begin{array}{l}\text { Average } \\
\text { of } 17 \text { runs }\end{array}$ & 92.1 & 15.6 & 72.2 & 60.1 \\
\hline \multirow[t]{2}{*}{ Sup'nt-IgG2a } & Run 1 & 88.3 & 16.7 & 88.3 & 88.3 \\
\hline & Run 2 & 100.3 & 17.0 & 93.2 & 93.2 \\
\hline \multirow[t]{2}{*}{ Sup'nt-IgG2b } & Run 1 & 92.5 & 11.3 & 79.5 & 79.5 \\
\hline & Run 2 & 95.5 & 10.6 & 65.9 & 65.9 \\
\hline \multirow[t]{2}{*}{ Sup'nt-IgG3 } & Run 1 & 93.3 & 8.3 & 72.7 & 72.7 \\
\hline & Run 2 & 98.7 & 12.0 & 81.8 & 81.8 \\
\hline \multicolumn{2}{|l|}{ Protein A-hyper D } & \multicolumn{2}{|c|}{ Based on OD $280 \mathrm{~nm}$} & \multicolumn{2}{|c|}{ Based on ELISA } \\
\hline Sup'nt-IgGl & & $93.9 \%$ & $21.7 \%$ & $80.1 \%$ & $72.9 \%$ \\
\hline \multicolumn{2}{|l|}{$\begin{array}{l}\text { Sup nt-IgGl } \\
\text { Average of } 7 \text {-runs }\end{array}$} & & & & \\
\hline \multicolumn{2}{|l|}{ Sup'nt-IgG2a } & 84.1 & 18.3 & 90.2 & 90.2 \\
\hline \multicolumn{2}{|l|}{ Sup'nt-IgG2b } & 83.0 & 15.7 & 104.0 & 104.0 \\
\hline \multicolumn{2}{|l|}{ Sup'nt-IgG3 } & 89.8 & 15.9 & 89.7 & 89.7 \\
\hline
\end{tabular}

$\%$ Yield The \% yield of the Mab was determined as a ratio of the total Mab in the eluate fraction (fraction 2) to the total Mab present in the feed.

$\%$ TR The \% total recovery of the Mab was determined as a ratio of the total Mab present in chromatographic fractions (fall-through, wash and elution) to the total Mab present in the feed.

Figure 2 shows SDS-PAGE gel of the purified fractions from a typical chromatographic separation. Chromatographic fractions from runs in Table 1 were selected for electrophoretic analysis. Lane 1 shows a molecular weight ladder. Lanes 2 and 3 show applications of pure Mab and BSA at a total protein level of 2 mgs, respectively. Lanes 4 show a representative sample the feed cell culture supernatant. Lanes 5 and 6 show an application of IgG1-Mab purified with r_PEZ column, at a total protein level of 3 mgs. Lanes 7 and 8 show an application of Mab purified with protein-A column, at a total protein level of $3 \mathrm{mgs}$. The eluate fraction from both protein A hyper D column and r_PEZ gave a band around $150 \mathrm{kDa}$ similar to the pure Mab in Lane 3. In addition to the major Mab band at $150 \mathrm{kDa}$, a minor band at $56 \mathrm{kDa}$ accounting for less than $2 \%$ of the area obtained by digital image processing was observed. Lane 9 and 10 show an application of column fall through at a total protein level of $3 \mathrm{mgs}$. The purity of the Mab in the eluate fraction (Lanes 4 and 5 ) is estimated to be greater than $98 \%$, respec- 
tively, by digital image processing. Similar electrophoretic patterns were obtained with the fractions from other runs listed in Table 1 (data not shown).

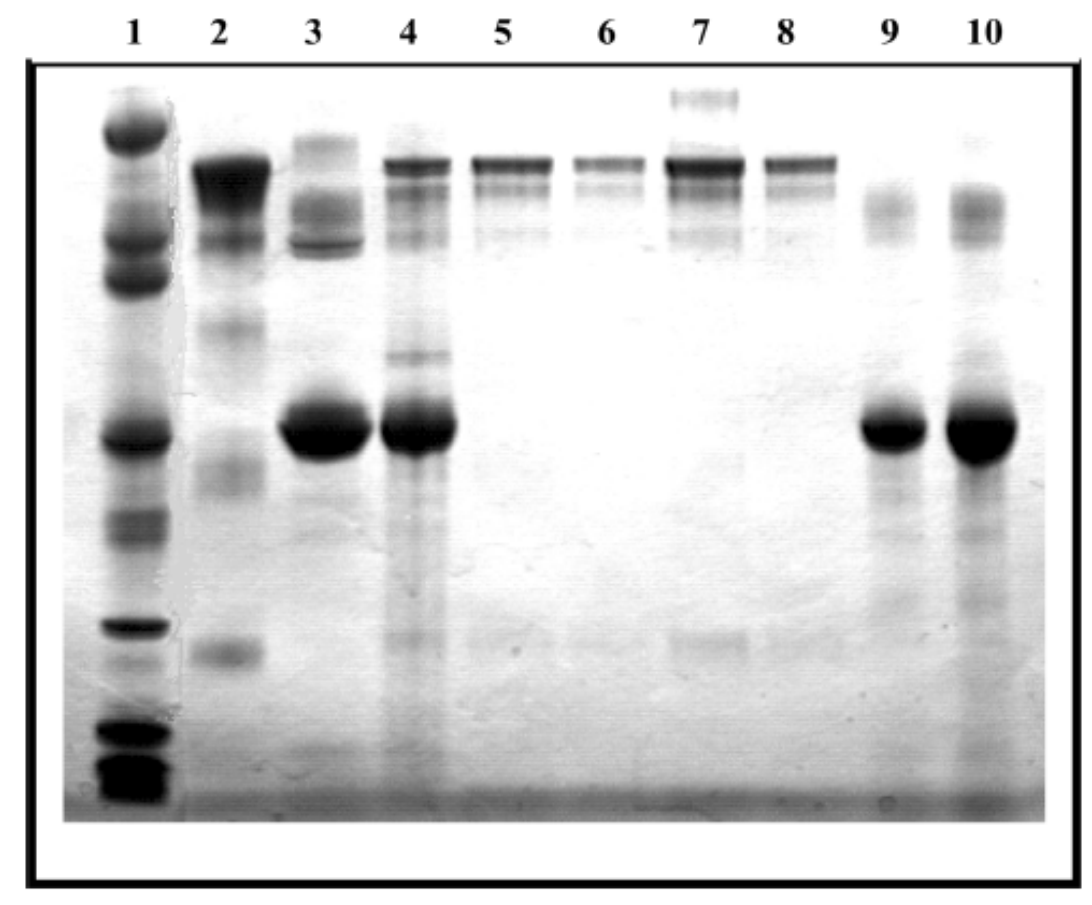

Figure 2. Sodium dodecylsulfate (0.1\%)-polyacrylamide gel (4-12\% gradient) electrophoresis of Mab's purified using r-PEZ and protein A-HD. Lane 1 shows a molecular weight ladder. Lanes 2 and 3 show applications of pure Mab and BSA. Lanes 4 shows a representative sample of the feed cell culture supernatant. Lanes 5 and 6 show an application of IgG1-Mab purified with r_PEZ column. Lanes 7 and 8 show an application of Mab purified with protein-A column. Lane 9 and 10 show an application of column fall through.

Figure 3 shows a SDS-PAGE gel of the starting cell culture supernatant (feed) and the purified fractions from a typical chromatographic separation on a r_PEZ column, under denaturing (reduced) conditions. Chromatographic fractions from Table 1 were selected for electrophoretic analysis. Lane 1 shows a molecular weight ladder. Lanes 2 and 3 show application of pure BSA and Mab at a total protein level of $5 \mathrm{mgs}$, respectively. Lanes 4 to 7 show an application of the elution fraction from cell culture supernatants rich in $\lg G 1, \lg G 2 a, \lg G 2 b$, and $\lg G 3$, respectively, at a total protein level of $7 \mathrm{mgs}$. Lane 9 shows the fall through fraction from a typical run at a total protein level of $10 \mathrm{mgs}$. The fall through fraction gave a band around $56 \mathrm{kDa}$ similar to the pure BSA in Lane 2. Lane 10 shows the feed fraction to the column for a typical 
run, at a total protein level of $10 \mathrm{mgs}$. The eluate fraction gave two bands around 55 and $24 \mathrm{kDa}$, representative of the heavy and the light chain of Mab.

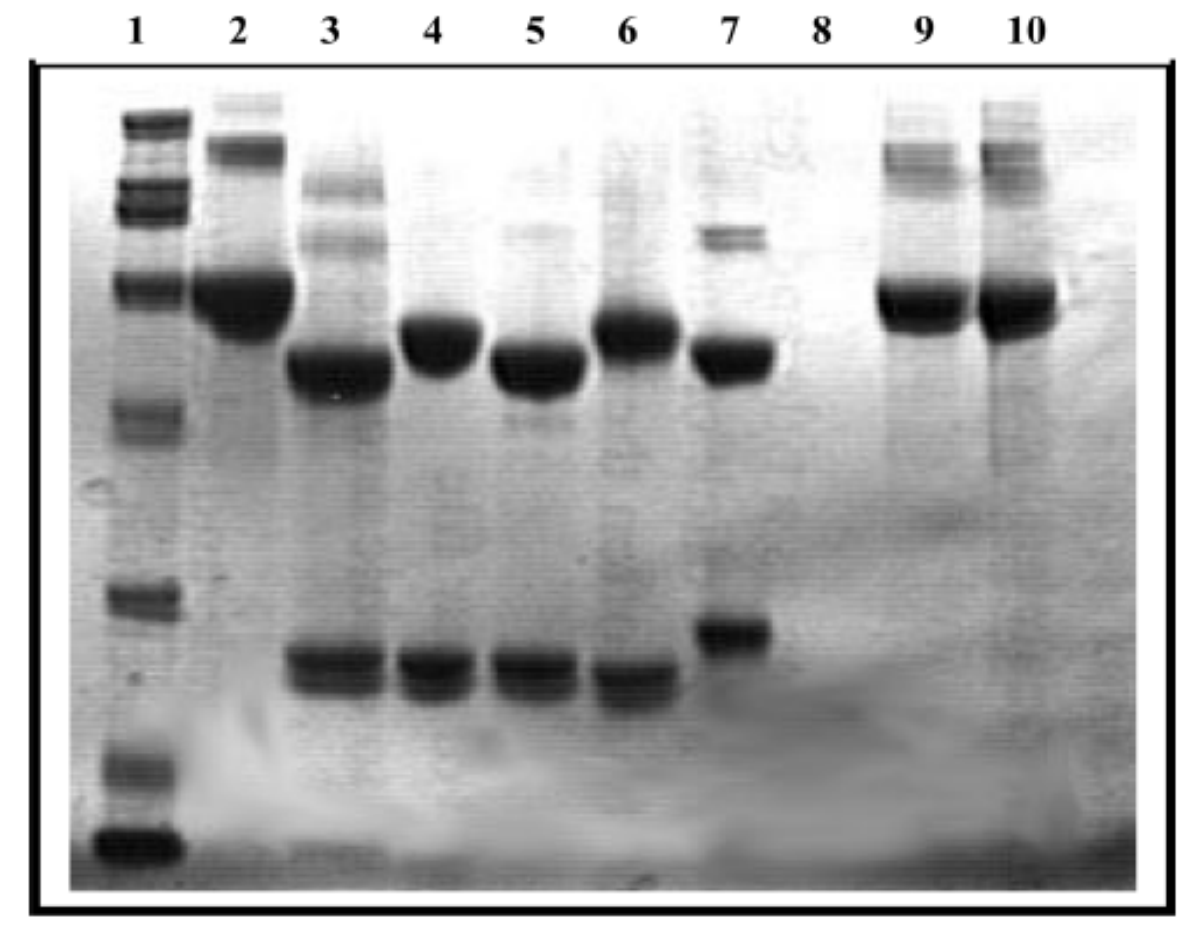

Figure 3. SDS-PAGE of purified fractions from a typical chromatographic sepe on a r_PEZ column, under denaturing (reduced) conditions. Lane 1 shows a mol weight ladder. Lanes 2 and 3 show application of pure BSA and Mab. Lanes 4 to 7 an application of the elution fraction from cell culture supernatants rich in IgG1, ] IgG2b, and IgG3. Lane 9 shows the fall through fraction from a typical run. L: shows the feed fraction to the column for a typical run.

As expected, the heavy chains of Mab subspecies have different mobility as evidenced by their migration patterns, and this arises from the difference in the glycosyation levels. The migration pattern was compared to that of pure Mab standards and found to be identical (data not shown). Lane 9 shows a representative fall through fraction at a total protein level of $3 \mathrm{mgs}$. The fall through fraction gave a band around $56 \mathrm{kDa}$ similar to the pure BSA in Lane 2. Figure 4 shows the electrophoretic mobility of Mabs purified using different matrices upon treatment with $\mathrm{N}$-glycosidase F. Lane 1, 3, and 5 Figure 2. Sodium dodecylsulfate (0.1\%)-polyacrylamide gel (4-12\% gradient) electrophoresis of Mab's purified using r-PEZ and protein A-HD. Lane 1 shows a molecular weight ladder. Lanes 2 and 3 show applications of pure Mab and BSA. 
Lanes 4 shows a representative sample of the feed cell culture supernatant. Lanes 5 and 6 show an application of IgG1-Mab purified with r_PEZ column. Lanes 7 and 8 show an application of Mab purified with protein-A column. Lane 9 and 10 show an application of column fall through show a $100 \mathrm{ng}$ application of Mab purified from r_PEZ, protein A-hyper D, and Mabreference standard, respectively. Lane 2, 4, and 6 show deglycosylated Mab and the apparent faster mobility of the heavy chain due to removal of $\mathrm{N}$-linked sugars is readily visible. No shift in the apparent mobility of the light chain of the Mab was observed, which is consistent with the absence of glycosylation of the light chain. Upon deglycosylation, heavy chains of all Mab samples had a similar shift in mobility.

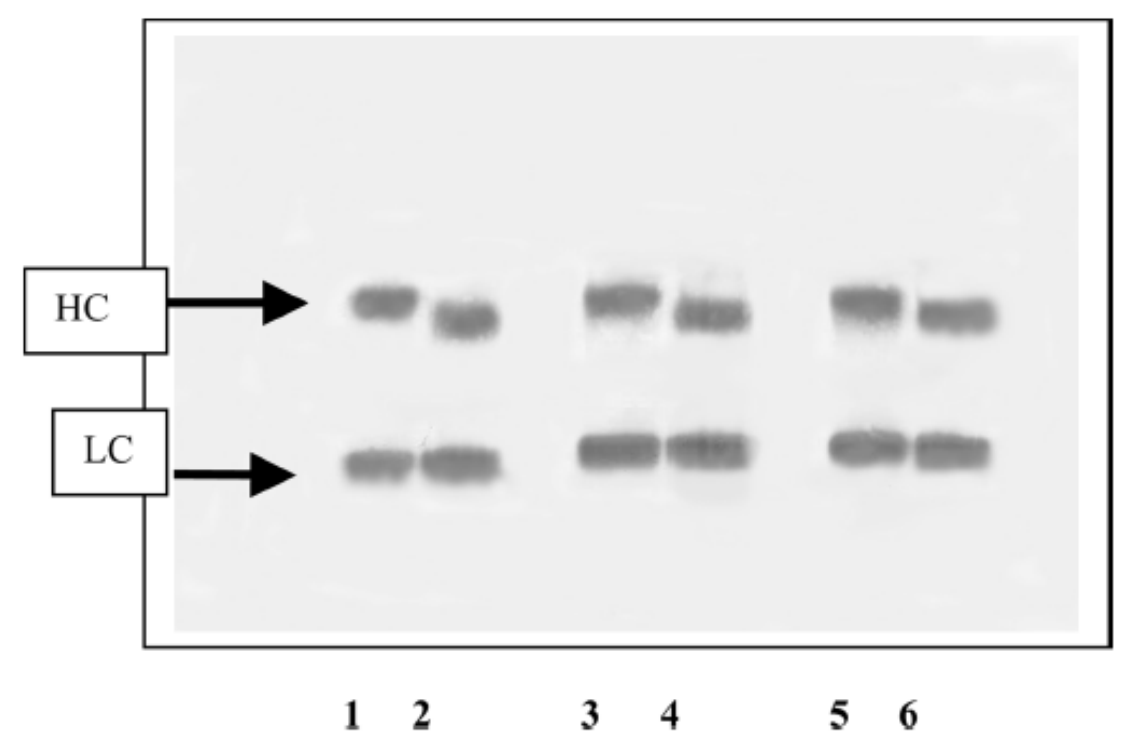

Figure 4. Electrophoretic mobility of Mabs purified using different matrices upon treatment with $\mathrm{N}$-glycosidase F. Lane 1, 3, and 5 show a $100 \mathrm{ng}$ application of Mab purified from r_PEZ, protein A-hyper D, and Mab-reference standard, respectively. Lane 2, 4, and 6 show deglycosylated Mab. 
We have used the ELISA based method as described in detail elsewhere[35] to determine the binding kinetics and $\mathrm{Kd}$. The method used in this study is based on the detection of the free Mab in the reaction mixture by an indirect ELISA procedure, after the Mab and the antigen reach equilibrium in solution. The underlying assumption is that the interaction between unbound Mab and the immobilized antigen (hPC in this case) does not differ significantly from the equilibrium attained between both in solution. Table 2 shows the value of the disassociation constant $(\mathrm{Kd})$ obtained for Mabs purified with r-PEZ and protein A-HD, and a reference Mab sample. Previous research has documented and characterized the affinity of the Mab used in this study, and hPC the parent antigen.[31] Disassociation constant (Kd) values of $0.236+0.05 \mathrm{nM}$ and $0.262+0.03 \mathrm{nM}$ were obtained for Mab purified using r_PEZ column and a protein-A hyper D column, respectively. A Kd value of $0.262+0.03 \mathrm{nM}$ was obtained for Mab reference standard. Comparable values of Kd suggest that the Mab purified via the r_PEZ col-

umn has similar activity to Mab reference standard, and the antigenic property for the Mab was not adversely impacted either by the zirconia matrix itself or the reagents and buffer employed in the chromatographic separation.

\section{DISCUSSION}

The popularity of silica as a chromatographic support results from the cumulative impact of its mechanical strength, availability in a wide range of pore sizes, nearly ideal pore structure, and versatility of the silanization chemistry. However, the dissolution of silica in aqueous mobile phases is widely recognized and documented, and is also prone to acid-catalyzed hydrolysis of the siloxane bonds below pH 2 and dissolution above $\mathrm{pH}$ of 8.0 by alkali attack.[32 - 34] Thus, the preparation of alternative stationary phase supports is an important area that aims to develop new support materials that offer novel selectivities, or to overcome the shortcomings of 
silica, alumina, and polymeric supports. The development of zirconia as a stationary phase material is an example where both aspects may be achieved.

Table 2. Disassociation constant $\left(\mathrm{K}_{\mathrm{d}}\right)$ obtained for Mabs purified with r-PEZ and protein A-HD and, a reference Mab sample

\begin{tabular}{lc}
\hline Sample & $\mathrm{K}_{\mathrm{d}}, \mathrm{nM}$ \\
\hline Mab purified on r_PEZ & $0.236 \pm 0.05$ \\
Mab purified on Protein A-hyper D & $0.301 \pm 0.01$ \\
Mab reference standard & $0.262 \pm 0.03$ \\
\hline
\end{tabular}

Zirconia surface has a unique surface chemistry and offers many possibilities for use in chromatography; it can be used as a bare support, it can be dynamically modified (i.e., phosphates and EDTPA), it may be coated with polymers or with inorganic layers. Additionally, its high density and excellent thermal and chemical stability provide several advantages over traditional silica or polymeric supports. Zirconia particles are extremely stable in both acidic and basic solutions.[23] The surface of bare zirconia is populated with 4 to 5 millimoles per square millimeter (mmoles/mm2) of Lewis acid sites, which are strong electrophiles and promote irreversible adsorption.[21,23] Therefore, surface modification of zirconia to titrate or neutralize the Lewis acid sites is essential before zirconia surface can be rendered useful as a support for chromatographic applications. Unless these electrophilic sites are charge titrated, zirconia particles undergo non-reversible protein adsorption and exhibit severe tailing. The great affinity of zirconia for phosphate, and the low solubility of zirconium phosphate in aqueous media, made the intentional modification of zirconia with EDTPA an attractive concept. EDTPA is a special chelator that renders zirconia Lewis acid deactivated (Figure 5). To overcome these effects, we have modified the zirconia surface with EDTPA and we have ensured that the buffers employed also contain 4mM EDTPA. Since EDTPA coating is adsorbed and not chemically 
bonded, we sought to evaluate the stability of EDTPA-modified zirconia surface under a wide variety of $\mathrm{pH}$ and buffer conditions. Our results indicate that EDTP. A modified zirconia is stable from $\mathrm{pH} 1$ to $\mathrm{pH} \mathrm{10,} \mathrm{and} \mathrm{the} \mathrm{EDTPA} \mathrm{does} \mathrm{not} \mathrm{desorb} \mathrm{from} \mathrm{the} \mathrm{surface.} \mathrm{In} \mathrm{these} \mathrm{experi-}$ ments, EDTPA-zirconia columns were flushed with 7000 column volumes of a pH 10 buffer and a pH 1 buffer, respectively, as separate experiments. Test solutes were periodically injected and the retention, selectivity, and efficiency were monitored. The selectivities and efficiencies of test solutes were nearly the same before and after the high $\mathrm{pH}$ and low $\mathrm{pH}$ exposure (Figure 6). Retention values of test solutes decreased by less than $3 \%$ to $4 \%$. Thus, it is surprisingly stable.

The underlying rationale for this study is that a fundamental understanding of the nature of interactions between EDTPA modified zirconia and $\operatorname{lgG}$, and of the impact of the chemistry and property of the base matrix on the biological properties of the purified proteins, will enable the development of robust and scalable alternate sorbents for use in preparative bioseparations. The underlying hypothesis was that zirconia being a charge-dense material Figure 5. Schematic of zirconia surface and N, N, N0, N0- Ethylenediamine tetra methylenephosphonic acid (EDTPA) may cause protein to denature upon retention. Proteins retained on immobilized metal affinity chromatographic supports (IMAC) have been shown to loose biological activity and, in some cases, have been denatured.

(a)

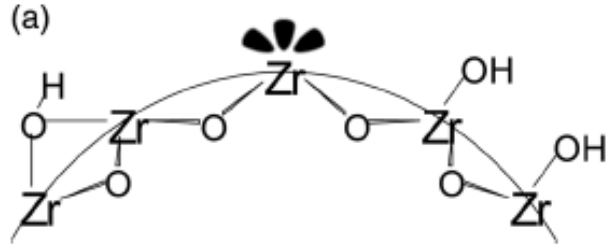

(b)

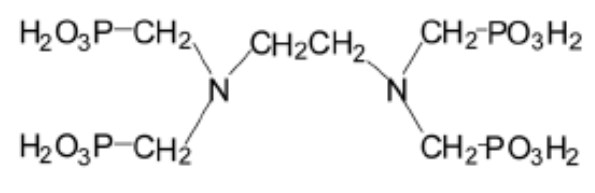

Figure 5. Schematic of zirconia surface and $\mathrm{N}, \mathrm{N}, \mathrm{N}^{\prime}, \mathrm{N}^{\prime}$ - Ethylenediamine tetra methylenephosphonic acid (EDTPA). 
In the absence of a spacer arm, it is conceivable that the retained Mab is in close proximity to the zirconia surface and subject to charge-induced denaturations. Hence, the activity of Mab products obtained from separation on a r_PEZ column and protein A-hyper D column were assayed for biological activity. We have used deglycosylation profile and the value of the $\mathrm{Kd}$ as identifiable markers. Denaturation of the Mab has shown to manifest itself in the loss of antigenicity, leading to an altered value of $\mathrm{Kd}$. Our study has shown that these parameter are unaffected by either the zirconia matrix itself or the process conditions used in separation. In conclusion, our present study has shown that the zirconia surface has no negative impact on the properties of purified Mab. In conjunction with our previous studies that have been reported elsewhere, EDTPA modified zirconia columns can now be used in the preparative scale separations of immunoglobulins. In addition, other chemistries could be exploited to produce phases with different retention mechanisms. Once EDTPA has been adsorbed, it may be possible to produce phases exhibiting different selectivities. These postderivatization procedures could include cross linking with diiodoalkanes to increase both phase stability and alter the selectivity of the support. 

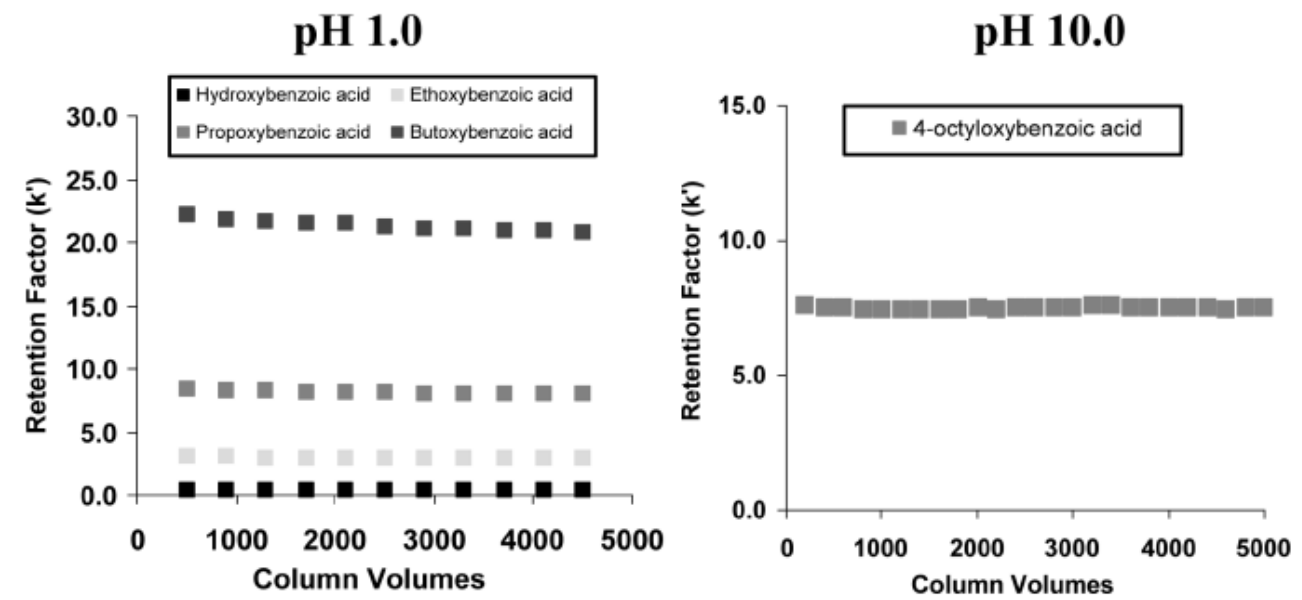

Figure 6. Exposure and evaluation conditions: Mobile phase, 15/85 acetonitrile/ $0.1 \mathrm{M}$ Nitric acid, $\mathrm{pH} 1.0$, or $0.1 \mathrm{M}$ Ammonium hydroxide, $\mathrm{pH} 10.0$; Flow rate, $1.0 \mathrm{~mL} / \mathrm{min}$; Temperature, $30^{\circ} \mathrm{C}$; Injection volume, $5 \mu \mathrm{L}$; Detection at $254 \mathrm{~nm}$; Column, $50 \mathrm{~mm} \times 4.6 \mathrm{~mm}$ i.d. rPEZ.

\section{REFERENCES}

1. Narayanan, I.; Prakash, K.; Verma, R.; Gujral, V. Administration of colostrum for the prevention of infection in the low birth weight infant in a developing country. J. Trop. Ped. 1983, 29, 197-200. Figure 6. Exposure and evaluation conditions: Mobile phase, 15/85 acetonitrile/ 0.1M Nitric acid, $\mathrm{pH} 1.0$, or $0.1 \mathrm{M}$ Ammonium hydroxide, $\mathrm{pH}$ 10.0; Flow rate, $1.0 \mathrm{~mL} / \mathrm{min}$.; Temperature, 308C; Injection volume, $5 \mathrm{~mL}$; Detection at $254 \mathrm{~nm}$; Column, $50 \mathrm{~mm}$ _ $4.6 \mathrm{~mm}$ i.d. rPEZ

2. Landon, J.; Akman, S. In Clinical Applications of Monoclonal Antibodies, Proceedings of an International Symposium on the Clinical Applications of Monoclonal Antibodies; Guildford, United Kingdom, September 15-17; 1987, Hubbard, R., Marks, V., Eds.; Plenum Press: New York, 1998.

3. Woodhead, J.S.; Aston, J.P. In Clinical Applications of Monoclonal Antibodies, Proceedings of an International Symposium on the Clinical Applications of Monoclonal Antibodies; Guild- 
ford, United Kingdom, September 15-17; 1987, Hubbard, R., Marks, V., Eds.; Plenum Press: New York, 1988.

4. Goding, J.W. Use of staphylococcal protein A as an immunological reagent. J. Immunol. Meth. 1978, 20, 241-253.

5. Abbas, A.K.; Lichtman, A.H.; Jordan, S.P. Cellular and Molecular Immunology, 2nd Ed.; W.B Saunders: Philadelphia, 1994.

6. Johnstone, A.P.; Thorpe, R. Immunochemistry in Practice; Blackwell Science: Oxford, 1996. 7. Harris, W.J. In Animal Cell Technology: Basic and Applied Aspects, Proceedings of the Sixth International Meeting of the Japanese Association for Animal Cell Technology; Nagoya, Japan, November 9-12; 1993, Kobayashi, T., Kitagawa, Y., Okumura, K., Eds.; Kluwer Academic Publishers: Boston, 1994.

8. Greenbaum, B. Differences in immunoglobulin preparations for the intravenous use: a comparison of six products. Am. J. Pediatr. Hematol. Oncol. 1990, 12, 490-496. 9. Malm, B. A method suitable for the isolation of monoclonal antibodies from large volumes of serumcontaining hybridoma cell culture supernatants. J. Immunol. Meth. 1987, 104, 103-109.

10. Belew, M.; Juntti, N.; Larsson, A.; Porath, J. One-step purification method for monoclonal antibodies based on salt-promoted adsorption chromatography on a "thiophilic" adsorbent. J. Immunol. Meth. 1987, 102, 173-182.

11. Surolia, A. Interaction of protein A with the domains of Fc fragment. Trends Biochem. Sci. 1982, 7, 74-83.

12. Lindmark, R.; Thoren-Tolling, K.; Sjoquist, J.Binding of immunoglobulins to protein A and immunoglobulin levels inmammalian sera. J. Immunol.Meth. 1983, 62, 1-13.

13. Forsgren, A.; Sjoquist, J. "Protein A" from S. Aureus. I. Pseudo-immune reaction with human gamma-globulin. J. Immunol. 1966, 97, 822-827. 
14. Bill, E.; Lutz, U.; Karlsson, B.; Sparrman, M.; Allgaier, H. Optimization of protein G chromatography for biopharmaceutical monoclonal antibodies. J. Mol. Recognit. 1995, 8, 90-94.

15. Fuglistaller, P. Comparison of immunoglobulin binding capacities and ligand leakage using eight different protein A affinity chromatography matrices. J. Immunol. Meth. 1989,124, 171177.

16. Bensinger, W.; Buckner, C.; Clift, R.; Thomas, E. Clinical trials with Staphylococcal protein A. J. Biol. Response Modif. 1984, 3, 347-351.

17. Labrou, N.; Clonis, Y. The affinity technology in downstream processing. J. Biotechnol. 1994, 36, 95-119.

18. Al-Mashikhi, S.; Nakai, S. Separation of immunoglobulins and transferrin from blood serum and plasma by metal chelate interaction chromatography. J. Dairy Sci. 1988, 71, 1756-1763. 19. Boden, V.; Winzerling, J.; Vijayalakshmi, M.; Porath, J. Rapid one-step purification of goat immunoglobulins by immobilized metal ion affinity chromatography. J. Immunol. Meth. 1995, $181,225-232$.

20. Porath, J.; Maisano, F.; Belew, M. Thiophilic adsorption-a new method for proteins fractionation. F.E.B.S Lett. 1985, 185, 306-310.

21. Clausen, A.; Subramanian, A.; Carr, P.W. Purification of monoclonal antibodies from cell culture supernatants using a modified zirconia based cation-exchange support. J. Chromatogr. A. $1999,831,63-72$.

22. Blackwel, J.A.; Carr, P.W. Fluoride-modified zirconium oxide as a biocompatible stationary phase for high-performance liquid chromatography. J. Chromatogr. 1991, 549, 59-75.

23. Rigney, M.P.; Weber, T.P.; Carr, P.W. Preparation and evaluation of a polymercoated zirconia reversed-phase chromatographic support. J. Chromatogr. 1989, 484, 273-291. 24. Schafer, W.A.; Carr, P.W. Chromatographic characterization of a phosphatemodified zirconia support for bio-chromatographic applications. J. Chromatogr. 
1991, 587, 149-160.

25. Weber, T.P.; Carr, P.W.; Funkenbusch, E.F. Evaluation of a zirconia-based

carbon-polymer composite reversed-phase chromatographic support. J. Chromatogr. $1990,519,31-37$.

26. McNeff, C.V.; Zhao, U.; Carr, P.W. High-performance anion exchange of small anions with polyethyleneimine-coated porous zirconia. J. Chromatogr. 1994, 684, 201-208.

27. Subramanian, A.; McNeff, C.V.; Carr, P.W. Use of spray-dried zirconia microspheres in the separation of immunoglobulins from cell culture supernatant.

J. Chromatogr. 2000, 890, 15-23.

28. Subramanian, A.; Van Cott, K.; Milbrath, D.; Velander, W.H. The role of local antibody density on immunosorbent performance. J. Chromatogr. A 1994, 672, 11-24.

29. Sarkar, S.; Carr, P.W.; McNeff, C.V.; Subramanian, A. Characterization and optimization of a chromatographic process based on ethylenediamine-N,N,NO,NO- tetra(methylphosphonic) acid-modified zirconia particles. J. Chromatogr. 2003, 790, 143-152.

30. Laemmli, U.K. Cleavage of structural proteins during the assembly of the head of bacteriophage T4. Nature 1970, 227, 680-685.

31. Orthner, C.L.; Madurawe, R.D.; Velander, W.H.; Drohan, W.H.; Battey, W.N.; Strickland, D.K. Evidence for interaction of protein C domains. J. Biol. Chem. 1989, 264, 31-35.

32. Glajch, J.; Kirkland, L.; Kohler, J. Effect of column degradation on the reversedphase high-performance liquid chromatographic separation of peptides and proteins. J. Chromatogr. 1987, 384, 81-96.

33. Iler, R. The Chemistry of Silica: Solubility, Polymerization, Colloidal and Surface Properties and Biochemistry; Wiley: New York, 1979. 
34. Unger, K. Porous Silica: its properties and use as a support in column liquid chromatography. In Journal of Chromatography Library; Elsevier Scientific Pub. Co.: Amsterdam, 1979; Vol. 16.

35. Friguet, B.; Chaffotte, A.F.; Djavadi-Ohaniance, L.; Goldberg, M.E. Measurements of the true affinity constant in solution of antigen-antibody complexes by enzyme-linked immunosorbent assay. J. Immunol. Meth. 1985, 77, 305-319. 